\section{Kidney \\ Blood Pressure Research}

Kidney Blood Press Res 2017;42:919-932

DOI: $10.1159 / 000485082$

Published online: November 22, 2017

2017 The Author(s)

Published by S. Karger AG, Basel

Accepted: June 06, 2017

This article is licensed under the Creative Commons Attribution-NonCommercial-NoDerivatives 4.0 InternaThis article is licensed under the Creative Commons Attribution-NonCommercial-NoDerivatives 4.0 Interna-
tional License (CC BY-NC-ND) (http://www.karger.com/Services/OpenAccessLicense). Usage and distribution tional License (CC BY-NC-ND) (http://www.karger.com/Services/OpenAccessLicense). Usage and dist
for commercial purposes as well as any distribution of modified material requires written permission.

\title{
Catechins Blunt the Effects of oxLDL and its Primary Metabolite Phosphatidylcholine Hydroperoxide on Endothelial Dysfunction Through Inhibition of Oxidative Stress and Restoration of eNOS in Rats
}

\author{
Hao-Hsiang Changa,b Chen-Yen Chien ${ }^{c, d} \quad$ Kuo-Hsin Chen ${ }^{e, f} \quad$ Shih-Chung Huang ${ }^{g}$ \\ Chiang-Ting Chien ${ }^{a}$ \\ aDepartment of Life Science, National Taiwan Normal University, Taipei; ${ }^{b}$ Department of Family \\ Medicine, National Taiwan University Hospital and College of Medicine, Taipei; 'Department of Surgery, \\ Mackay Memorial Hospital and Mackay Medical College, Taipei; ${ }^{\mathrm{D}}$ Mackay Junior College of Medicine, \\ Nursing and Management, New Taipei City; 'Division of General Surgery, Far-Eastern Memorial \\ Hospital, New Taipei City; fDepartment of Electrical Engineering, Yuan Ze University, Taoyuan City; \\ ${ }^{9}$ Department of Cardiology, Kuang-Tien General Hospital, Taichung; Taiwan, ROC
}

\section{Key Words}

Catechins $\bullet \mathrm{PCOOH} \cdot$ Oxidative stress $\bullet$ Endothelial cells $\bullet$ Nitric oxide $\bullet$ Vasoconstriction

\begin{abstract}
Background/Aims: We explored the effects of catechins (decaffeinated green tea extracts containing (-)-epicatechin, (-)-epigallocatechin, (-)-epicatechin gallate and (-)-epigallocatechin gallate) on atherosclerosis risk factors, oxidized low-density lipoprotein (oxLDL) and its primary metabolite, phosphatidylcholine hydroperoxide ( $\mathrm{PCOOH})$ induced oxidative injury in cultured endothelial cell line and rats. Methods: We used endothelial cell line and male Wistar rats to determine the effect of catechins on oxLDL or PCOOH induced oxidative injury including apoptosis, $\mathrm{H}_{2} \mathrm{O}_{2}$ level, vascular responses and urinary 8-isoprostane and nitrite/nitrate concentration. Plasma catechins concentration was determined by a CoulArray HPLC. Responses of aortic and renal vasoconstriction were evaluated by a transonic meter and a full-field laser perfusion imager. Results: $\mathrm{PCOOH}$ administration significantly increased $\mathrm{H}_{2} \mathrm{O}_{2}$ amounts and cell apoptosis and decreased endothelial nitric oxide synthase (eNOS) expression in the cultured endothelial cells. Catechins pretreatment significantly reduced $\mathrm{PCOOH}$-elevated $\mathrm{H}_{2} \mathrm{O}_{2}$ amounts, endothelial cell apoptosis and partly recovered eNOS expression. Intravenous administration of oxLDL, $\mathrm{PCOOH}$ or $\mathrm{H}_{2} \mathrm{O}_{2^{\prime}}$ not native $\mathrm{LDL}$, significantly decreased renal and aortic blood flow associated with enhanced ICAM-1 expression and 4-hydroxynoneal (4-HNE)
\end{abstract}

Chiang-Ting Chien PhD

Shih-Chung Huang MD,

And Kuo-Hsin Chen MD
Department of Life Science, National Taiwan Normal University, No. 88

Sec. 4, Tingzhou Road, Taipei (Taiwan)

Tel. +886-2-77346312, Fax +886-2-29312904, E-Mail ctchien@ntnu.edu.tw 


\section{Kidney Blood Pressure Research}

accumulation, and decreased eNOS expression in the male Wistrar rats. One hour after oral intake of green tea extracts, 4 peaks of catechins were found in the rat plasma. The increased plasma catechins significantly inhibited oxLDL-, $\mathrm{PCOOH}$ - or $\mathrm{H}_{2} \mathrm{O}_{2}$-induced renal and aortic vasoconstriction, decreased urinary 8-isoprostane levels, renal ICAM-1 expression and 4-HNE accumulation, and restored nitrite/nitrate amounts and eNOS activity. Conclusions: Our data suggests that catechins pretreatment decrease $\mathrm{PCOOH}$-induced endothelial apoptosis and arterial vasoconstriction through the action of $\mathrm{H}_{2} \mathrm{O}_{2}$ inhibition and eNOS restoration.

(C) 2017 The Author(s)

Published by S. Karger AG, Basel

\section{Introduction}

The pathogenesis of cardiovascular disease is closely associated with an increase in oxidative stress [1]. One of the major reactive oxygen species (ROS) generated from activated leukocytes, resident injured cells, and other sources is hydrogen peroxide $\left(\mathrm{H}_{2} \mathrm{O}_{2}\right)$ $[2,3] ; \mathrm{H}_{2} \mathrm{O}_{2}$ could oxidize low-density lipoprotein (LDL) and induce endothelial injury and contribute to atherosclerosis. Oxidized LDL (oxLDL) increases the adhesion of monocytes to the endothelium, increases transformation of macrophages into foam cells, and impairs endothelium-dependent vasorelaxation $[4,5]$. The concentration of phosphatidylcholine hydroperoxide $(\mathrm{PCOOH})$, a primary lipid peroxidation product of LDL or VLDL, is positively correlated with the amount of $\mathrm{H}_{2} \mathrm{O}_{2}[2,3]$. An increase in $\mathrm{H}_{2} \mathrm{O}_{2}$ levels was found in macrophages cultured on oxLDL matrices [6]. Furthermore, oxLDL-related lipid peroxidation can produce two oxidative stress biomarkers, 4-hyroxy-2-nonenal (4-HNE) and 8-isoprostane [1]. These suggest a close interaction among oxLDL, $\mathrm{PCOOH}$ and $\mathrm{H} 2 \mathrm{O} 2$ which are contributing to the progression of cardiovascular diseases.

An increased PCOOH level is found in aging [7] and those with cardiovascular diseases $[2,3]$. Increased $\mathrm{H}_{2} \mathrm{O}_{2}$ can serve as second messengers in the induction of pro-inflammatory nuclear transcription factor- $\mathrm{kB}(\mathrm{NF}-\kappa \mathrm{B})$-regulated genes, including soluble ICAM-1, monocyte chemoattractant protein-1, and TNF- $\alpha$ leading to pathophysiologic dysfunction in the vessels [8]. The senescence of endothelial cells is accompanied by an increased susceptibility to apoptotic cell death, and this phenomenon has previously been attributed to insufficiency of nitric oxide (NO) production [9]. The loss and/or decrease of counteracting vasodilator mechanisms, such as NO and endothelial nitric oxidase synthase (eNOS), may evoke severe vasoconstriction in those with cardiovascular diseases $[9,10]$. We hypothesize that the elevated oxLDL or PCOOH may attack endothelial cells via the enhanced oxidative stress like the increased $\mathrm{H}_{2} \mathrm{O}_{2}$ production to impair the endothelial integrity and its function for NO/eNOS mediated vasorelaxation. Therefore, the use of an appropriate antioxidant to decrease oxidative stress may be important targets for nutritional and pharmacological therapy in patients with dyslipidemia or cardiovascular diseases.

Most of the antioxidants tested to date, however, carry some potential side effects that preclude their wide utility in human clinical trials [11]. Green tea extracts containing $(+)$-catechin (C), (-)-epicatechin (EC), (+)-gallocatechin (GC), (-)-epigallocatechin (EGC), $(-)$-epicatechin gallate (ECG), and (-)-epigallocatechin gallate (EGCG) may confer protective effects against cardiovascular diseases $[12,13]$. In antioxidative activities, catechins are shown to be more effective than vitamin $\mathrm{C}$ in scavenging $\mathrm{HOCl}$ and vitamin $\mathrm{E}$ for both $\mathrm{H}_{2} \mathrm{O}_{2}$ and $\mathrm{HOCl}$ [14]. Catechins can inhibit pro-inflammatory and pro-apoptotic oxidative injury via reducing production of ROS, translocation of NF- $\kappa$ B and activated protein-1 (AP-1), and expression of ICAM-1 [15]. The use of catechins supplementation to inhibit the progression of atherosclerosis and to attenuate vascular injury has been well endeavored in the end-stage renal diseases patients with chronic hemodialysis treatment [14]. We explored whether oral catechin supplements would provide an alternative approach in reducing oxLDL- and PCOOH-induced oxidative stress, inflammation, endothelial cell injury, and vasoconstriction in rats. 


\section{Kidney Blood Pressure Research}

Chang et al.: Catechins Reduce PCOOH-Induced Endothelial Injury

\section{Materials and Methods}

\section{Cell culture}

Human umbilical vein endothelial cells line (HUVECs, ATCC CRL-2873) were cultured in EGM2 medium supplemented with $2.5 \%(\mathrm{v} / \mathrm{v}$ ), or free fetal bovine serum as previously described [8]. Cells were used at passages 3-4, and all cells exhibited the specific characteristics of endothelial cells. HUVECs were seeded at $1 \times 10^{5}$ cells/mL on $0.8 \%$ gelatin-coated 24 -well plates. After $24 \mathrm{~h}$, the medium was replaced with $2.5 \%$ or free fetal bovine serum in EGM2 medium, and cells were incubated overnight. Generation of $\mathrm{H}_{2} \mathrm{O}_{2}$ and apoptosis were induced by exposing cells to $\mathrm{PCOOH} \mathrm{(185} \mathrm{pmole/mL).} \mathrm{Our} \mathrm{preliminary} \mathrm{data} \mathrm{showed}$ that $0.24 \mathrm{mg} / \mathrm{mL}$ of oxLDL may contain $61.6 \mathrm{pmole} / \mathrm{mL}$ of PCOOH. Four hours prior to PCOOH exposure, the catechins at $50 \mu \mathrm{g} / \mathrm{mL}$ or catalase (Sigma-Aldrich, St. Louis, MO, USA) at $20000 \mathrm{U} / \mathrm{mL}$, an enzyme that catalyzes the decomposition of $\mathrm{H}_{2} \mathrm{O}_{2}$ to water and molecular oxygen [16], was added in to the medium.

\section{Cell viability and cell apoptosis}

Cell viability was determined using MTT assay [8]. The MTT assay depends on the extent to which viable cells convert MTT bromide to an insoluble colored formazan product that can be determined spectrophotometrically. After treatment, cells are harvested and washed in PBS, and $200 \mathrm{~mL}$ of DMEM without phenol red, containing $5 \mathrm{mg} / \mathrm{mL}$ MTT, was added to each well. Four hours later, the medium was aspirated, and the converted dye is solubilized with isopropanol $(0.1 \mathrm{~N} \mathrm{HCl}$ in isopropanol). The resulting absorbance from each well was measured by an ELISA reader at a wavelength of $570 \mathrm{~nm}$ with background subtraction at $630 \mathrm{~nm}$. Finally, an MTT bar graph was drawn. Cell apoptotic death was determined by using Annexin-V-propiodium stains [8].

\section{Green tea extract (Catechins)}

Decaffeinated catechins was purchased from Numen Biotech Co., Ltd. (Taipei, Taiwan); the catechins consisted of $328 \mathrm{mg} / \mathrm{g}$ of (-)-epigallocatechin gallate (EGCG), $152 \mathrm{mg} / \mathrm{g}$ of (-)-epicatechin gallate (ECG), $132 \mathrm{mg} / \mathrm{g}$ of (-)-epicatechin (EC), $108 \mathrm{mg} / \mathrm{g}$ of (-)-epigallocatechin (EGC), $104 \mathrm{mg} / \mathrm{g}$ of (+)-gallocatechin (GC), and $44 \mathrm{mg} / \mathrm{g}$ of (+)-catechin (C). HUVECs were treated with catechins at a dose of $100 \mu \mathrm{g} / \mathrm{ml}$ before or after PCOOH treatment. In rats, catechins supplement was administered at a dose of $10 \mathrm{mg} / \mathrm{kg} / \mathrm{day}$ intragastrically for two weeks.

\section{Analysis of catechins in plasma by high performance liquid chromatography (HPLC)}

The HPLC method for plasma catechins analysis was described previously [13]. The standard samples of C, EC, GC, EGC, ECG, and EGCG were purchased from Sigma Chemical Co. (St. Louis, MO). Oxalic acid, ethanol, $\mathrm{NaH}_{2} \mathrm{PO}_{4}$ were purchased from Merck. Mobile Gradient mobile phase A and B solution were from ESA Inc. (Bedford, MA, USA). A standard stock mixture of C, EC, GC, EGC, ECG, EGCG at $100 \mu \mathrm{g} / \mathrm{ml}$ was prepared in $10 \mathrm{mM}$ oxalic acid solution and stored in small aliquots at $-80 \mathrm{C}$ until use.

The distribution of catechins in plasma and standards was determined by a gradient HPLC-Coulometric electrode array system (ESA Inc., Bedford, MA, USA). One mL of samples was subjected to $\mathrm{Al}_{2} \mathrm{O}_{3}$ solid phase extraction (ESA Inc., Bedford, MA, USA), and the resulting samples in $1 \mathrm{M} \mathrm{NaH}_{2} \mathrm{PO}_{4}(\mathrm{pH}=2.5)$ were applied to the HPLC with an autosampler (Model 542, ESA) and an electrochemical detector (Model 5600A, ESA). The separating conditions were as follows: column, HR-80 (C-18, $3 \mu \mathrm{m}, 4.6 \mathrm{~mm} \times 80 \mathrm{~mm}$, ESA); column temperature, $25^{\circ} \mathrm{C}$; gradient mobile phase A (containing phosphate buffer and an ion pairing agent, 45 0171, ESA) and gradient mobile phase B (containing methanol, phosphate buffer, and an ion pairing agent, ESA); flow rate, $1 \mathrm{~mL} / \mathrm{min}$. The optional channel potential was set to $220 \mathrm{mV}$. The peak height was used to calculate the plasma concentration using an external calibration curve of spiked control plasma.

\section{ROS, 8-isoprostane and NO assay}

The effects of catechins on how much PCOOH induced the $\mathrm{H}_{2} \mathrm{O}_{2}$ amounts in HUVECs was determined by a luminol-amplified chemiluminescence method developed in our laboratory [15]. For measurement of markers and mediators of oxidative stress [17], urinary 8-isoprostane concentration was determined by a commercial ELISA kit (Cayman Chemical, Ann Arbor, Michigan, USA). For the measurement of final products 


\section{Kidney Blood Pressure Research}

of $\mathrm{NO}$ in vivo, the concentration in urinary nitrite $\left(\mathrm{NO}_{2}^{-}\right)$and nitrate $\left(\mathrm{NO}_{3}^{-}\right)$was measured by the nitrite/ nitrate colorimetric assay kit (Cayman Chemical, Ann Arbor, Michigan, USA).

\section{Effects of native $L D L$, oxLDL, or $P C O O H$ on vascular reactivity in rats}

To display the effect of native LDL, oxLDL, or PCOOH on vascular reactivity in vivo, we measured the abdominal aortic and left renal blood flow after the injection of different dosages of PCOOH $(0,61.6,123$, $185 \mathrm{pmoles} / \mathrm{mL}$ ) in urethane-anesthetized rats. Our previous study had found that $0.1 \mathrm{mg} / \mathrm{mL}$ oxLDL could induce renal vasoconstriction [18]. In the present study, to enhance oxLDL induced vasoconstriction, oxLDL and native LDL were injected at the different dosages of $0,0.24,0.48,0.72 \mathrm{mg}$ protein $/ \mathrm{mL}$. Native LDL was prepared from the blood of healthy volunteers. Pooled human LDL was obtained from healthy subjects from a local blood bank, isolated by ultracentrifugation, oxidized by $\mathrm{CuSO}_{4}$, and analyzed as described previously [18].

Male Wistar rats (200-250 g) were purchased from BioLASCO Taiwan Co. Ltd. (Taipei) and housed at the Experimental Animal Center, National Taiwan Normal University. All surgical and experimental procedures were approved by National Taiwan Normal University Animal Care and Use Committee (NTNUACUC Approval No: 101031 and date of approval: December 28, 2012), National Taiwan University College of Medicine and College of Public Health Institutional Animal Care and Use Committee (IACUC Approval No: 20020049 and date of approval: March 5, 2003) and were in accordance with the guidelines of the National Science Council of Republic of China (NSC 1997). Briefly, rats were anesthetized with subcutaneous urethane $(1.2 \mathrm{~g} / \mathrm{kg})$. The tip of the PE-10 catheter via the left carotid artery was placed in the abdominal aorta just above the left renal artery branch. The effect of intra-arterial PCOOH (185 pmol/mL), LDL (0.72 $\mathrm{mg} / \mathrm{mL})$ and oxLDL $(0.72 \mathrm{mg} / \mathrm{mL})$ as well on abdominal aortic and renal blood flow was measured by using a flow probe (2SB1388 for aorta and 1RB2098 for renal artery, T206 Transonic System Inc., Ithaca, NY, USA) placed around the abdominal aorta and left renal artery for 1-2 hours. Parameters of blood flow were continuously measured with a T206 recording system (Transonic System Inc.) and displayed on a computeraided polygraph (PowerLab/16S, ADI Instruments Pty Ltd, Castle Hill, Australia). Some rats were pretreated with oral catechins ( $10 \mathrm{mg} / \mathrm{kg}$ body weight) at 1 hour before the injection of PCOOH or oxLDL. At the end of the experiments, the animals were sacrificed with intravenous injection of potassium chloride.

\section{Renal microcirculation measurement}

The catechins effect on oxLDL or PCOOH-induced renal vasoconstriction was evaluated with a fullfield laser perfusion imager as described previously [19]. A full-field laser perfusion imager (MoorFLPI, Moor Instruments Ltd., Devon, UK) was used to continuously record microcirculatory blood flow intensity in the tested kidney. The amount of blood cells moved within the region of interest (ROI) was processed to produce a 16-color coded image that correlates with the value of renal blood flow. The ROI in blue is recognized as lower flow, whereas that which is in red is identified as higher flow. The microcirculatory blood flow intensity of each ROI was displayed as a perfusion unit. The images were real-time analyzed by the MoorFLPI software version 3.0 (Moor Instruments Ltd.).

\section{Western blotting}

We explored the effect of catechins on intravenous oxLDL or PCOOH-mediated oxidative stress including eNOS, ICAM-1 expression and 4-hydroxynoneal (4-HNE) immunoreactivity in the rat kidney [8]. 4-HNE $\left(\mathrm{C}_{9} \mathrm{H}_{16} \mathrm{O}_{2}\right)$ is an $\alpha, \beta$-unsaturated hydroxyalkenal that is produced by lipid peroxidation in cells and has been implicated in the etiology of pathological changes under oxidative stress as a key mediator of oxidative stress. It is a stable product of lipid peroxidation and may contribute to the cytotoxic effects of oxidative stress. We used an established 4-HNE agent, which has a higher affinity for the 4-HNE histidine adduct, to assess the degree of lipid peroxidation by immunohistochemical detection. The whole kidney homogenates were used to analyze these immunohistochemical expressions. The following agents were used: rabbit antiphospho-eNOS (Cell Signal Technology, Beverly, MA), anti-4-hydroxynoneal (4-HNE) (Abcam, Cambridge, UK), ICAM-1 (R\&D Systems, Minneapolis, MN), and anti- $\beta$-actin (Sigma-Aldrich). The binding signal was visualized on film using a commercial enhanced chemiluminescence kit (Amersham Biosciences, Piscataway, $\mathrm{NJ}$ ). The density of the bands was determined semi-quantitatively by densitometry using an image analyzing system (Alpha Innotech, San Leandro, CA). 


\section{Kidney Blood Pressure Research}

\section{Statistical analysis}

All data are expressed as the mean \pm standard error of the mean. Differences within groups were evaluated by a paired t-test. One-way analysis of variance was used to compare differences among groups. Intergroup comparisons were made by Duncan's multiple-range test. Differences were regarded as significant for $P<0.05$. We used Sigma Plot 12.0 for the graph preparations. All statistical analyses were performed using the SPSS software system (SPSS Inc., Chicago, IL).

\section{Results}

Catechins reduced
PCOOH-enhanced
apoptosis and $\mathrm{H}_{2} \mathrm{O}_{2}$ in
HUVECS
PCOOH markedly
evoked an alteration in the morphology of endothelial cells and increased green fluorescence of Annexin V-FITC stained apoptosis in the endothelial cells culture (Figure 1A), whereas catechins treatment efficiently reduced the alteration in morphology and attenuated the green fluorescence of Annexin V-FITC stained apoptosis in these cultured endothelial cells. In the absence of FBS cultures, the absorbance value of endothelial cells markedly decreased as compared to 2.5\% FBS cultures (Figure 1B). Our data showed that $\mathrm{PCOOH}$ doses dependently decreased endothelial cell viability (Figure 1C). PCOOH administration significantly enhanced the apoptosis level (Figure 1D) and $\mathrm{H}_{2} \mathrm{O}_{2}$-luminol levels (Figure 1E), whereas catechins pre- and post-treatment at the dose of $100 \mu \mathrm{g} / \mathrm{mL}$ significantly reduced PCOOH-induced apoptosis and $\mathrm{H}_{2} \mathrm{O}_{2}$-luminol levels in the cultured endothelial cells. However, catechins pretreatment decreased more apoptosis than that in catechins post-treatment (Figure 1D). We also noted that catalase pretreatment inhibited more PCOOH-enhanced $\mathrm{H}_{2} \mathrm{O}_{2}$-luminol levels (Figure 1E) in the endothelial cells.

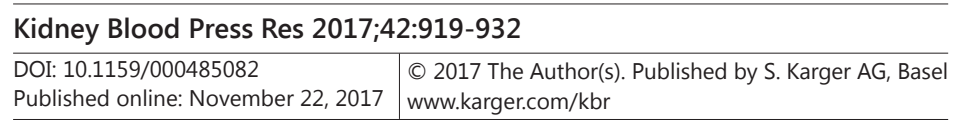

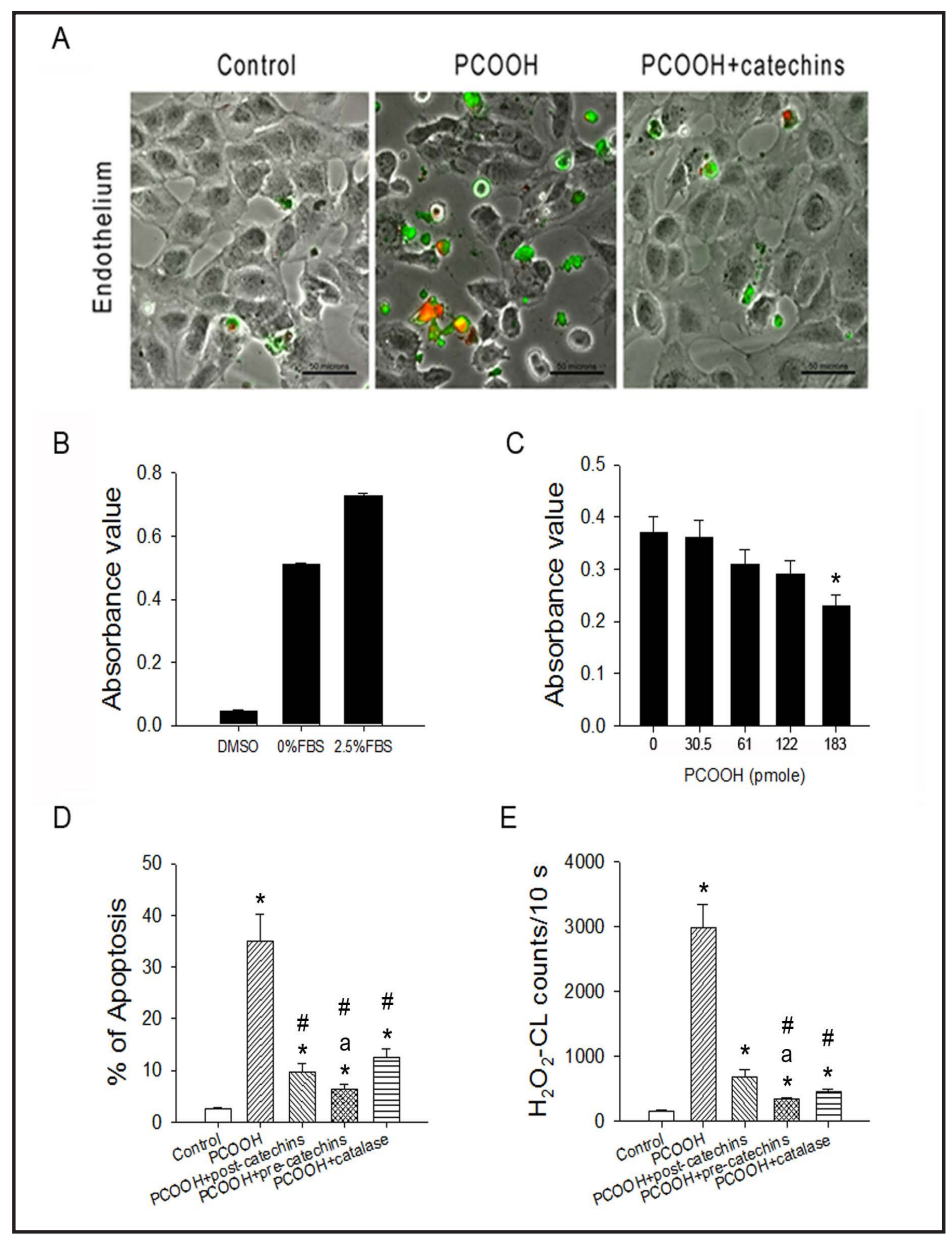

Fig. 1. Effect of catechins on $\mathrm{PCOOH}$ treated endothelial cell apoptosis (A) by Annexin V-FITC and PI stain, the results of free FBS (0\%) on MTT assay (B), statistic data of survival curves by MTT assay (C), percentage of apoptosis (D) and enhanced $\mathrm{H}_{2} \mathrm{O}_{2}$ amount by a chemiluminescence method (E) in vitro. $\mathrm{PCOOH}$ treatment significantly and dose-dependently increased endothelial cell apoptosis and the $\mathrm{H}_{2} \mathrm{O}_{2}$ amount compared to control group, whereas catechins or catalase pretreatment and post-treatment significantly ameliorated $\mathrm{PCOOH}$ enhanced endothelial cell apoptosis and the $\mathrm{H}_{2} \mathrm{O}_{2}$ level. However, pretreatment of catechins is better than post-treatment of catechins in reduction of endothelial cell apoptosis and $\mathrm{H}_{2} \mathrm{O}_{2}$ value. ${ }^{*} \mathrm{P}<0.05$, vs. control; \# $\mathrm{P}<0.05$ vs. $\mathrm{PCOOH}$ group. a $\mathrm{P}<0.05$ vs. post-catechins group. 


\section{Kidney Blood Pressure Research}

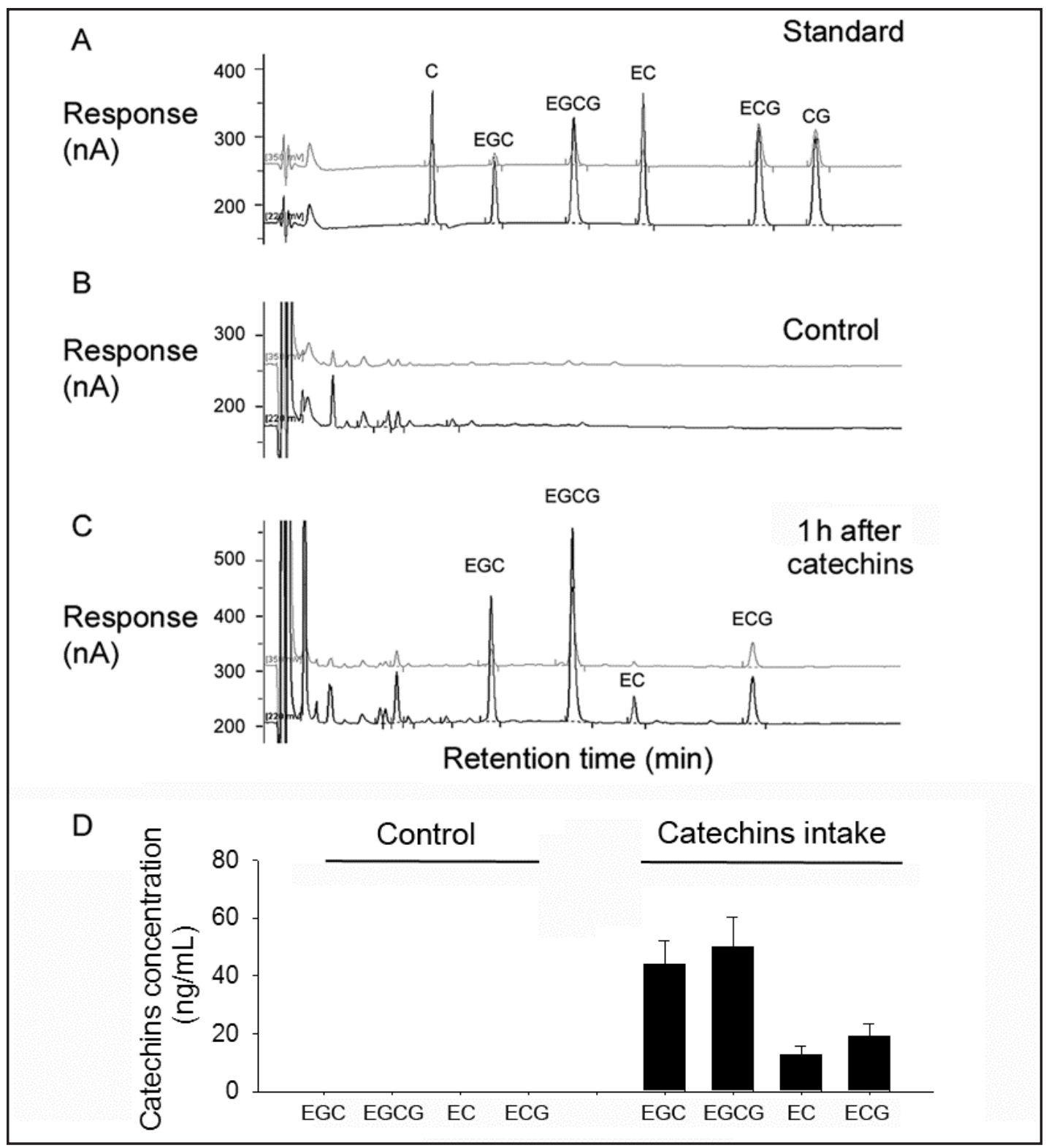

Fig. 2. Plasma catechins concentrations after oral GTE. The plasma concentrations of catechins in standards (A), control (B), after $1 \mathrm{~h} \mathrm{(C)} \mathrm{and} \mathrm{statistic} \mathrm{data} \mathrm{(D)} \mathrm{of} \mathrm{GTE} \mathrm{(10} \mathrm{mg/kg} \mathrm{body} \mathrm{weight)} \mathrm{intragastrically} \mathrm{in} \mathrm{one}$ rat are demonstrated by HPLC-array. Control, before catechins intake; Catechins intake, $1 \mathrm{~h}$ after catechins intake.

\section{Plasma catechins concentration}

We measured the plasma catechins concentration in normal rats $(n=6)$ after one single oral dose of catechins ( $10 \mathrm{mg} / \mathrm{kg}$ body weight) (Figure 2). Although six typical components of catechins (C, EC, GC, EGC, ECG, and EGCG) appeared in the standard assay, after 60 minutes of oral catechins, there were only four peaks, including EC, EGC, ECG, and EGCG, detected in the plasma from the six normal rats. The concentrations of these four catechins was indicated in Figure 2D. The mean concentration $(\mathrm{ng} / \mathrm{mL})$ calculated from the respective areas under the curve was $43.9 \pm 8.4 \mathrm{ng} / \mathrm{mL}$ for plasma EGC, $50.0 \pm 10.4 \mathrm{ng} / \mathrm{mL}$ for EGCG, $12.5 \pm 3.0$ for EC, and 19.1 \pm 4.2 for ECG after $1 \mathrm{~h}$ of catechins intake. There was no detection of EC, EGC, ECG, and EGCG before catechins ingestion. 


\section{Kidney \\ Blood Pressure Research}

Oral catechins administration inhibited oxLDL or PCOOH-mediated vasoconstriction in rats

We found that PCOOH positively correlated with increased oxLDL concentration $\left(r^{2}=0.9697\right)$, but did not display any relationship with native LDL $\left(r^{2}=0.1022\right.$, Figure 3A).

To explore the potential effects of catechins on native LDL, oxLDL- or $\mathrm{PCOOH}$-mediated vasoconstriction in vivo, we evaluated the effect of native LDL, oxLDL (0-0.72 mg protein/mL), and $\mathrm{PCOOH} \quad(0-185 \mathrm{pmole} / \mathrm{mL})$ on renal and aortic blood flow in urethaneanesthetized rats. The level of basal aortic blood flow and renal blood flow was $10.5 \pm 1.2 \mathrm{~mL} / \mathrm{min}$ and $3.6 \pm 0.4 \mathrm{~mL} /$ min, respectively. Our results showed that oxLDL, not native LDL, caused a substantial reduction in renal (from 100, 91,82 , to $73 \%$ ) and aortic blood flow (from 100, 95, 91 to 87\%), indicating renal and aortic vasoconstriction, in a dosedependent manner (Figure 3B). $\mathrm{PCOOH}$ also caused the substantial reduction in renal (from 100, 89, 79 to 71\%) and aortic blood flow (from 100, 93, 89 to 85\%) in a dose-dependent manner (Figure 3C). Orally administrated catechins $(10 \mathrm{mg} /$ $\mathrm{kg}$ ) were shown to attenuate oxLDL- or $\mathrm{PCOOH}$-induced vasoconstriction at similar degrees.

Oral catechins attenuated $\mathrm{PCOOH}$, oxLDL and $\mathrm{H}_{2} \mathrm{O}_{2}$-reduced renal microcirculation

We explored the effect of intravenous infused $\mathrm{PCOOH}$, oxLDL and $\mathrm{H}_{2} \mathrm{O}_{2}$ on renal microcirculation from the rat kidney in vivo using a Moor Image. Blue coloring indicated a lower level of microcirculation, whereas red coloring demonstrated a higher microcirculation. $\mathrm{PCOOH}$, oxLDL and $\mathrm{H}_{2} \mathrm{O}_{2}$ doses dependently decreased renal microcirculation, whereas catechins pretreatment efficiently recovered the depressed renal microcirculation by $\mathrm{PCOOH}$, oxLDL or $\mathrm{H}_{2} \mathrm{O}_{2}$ in rats (Figure 4).



Fig. 3. Intragastric catechins on intravenous LDL, oxLDL or PCOOH-mediated renal vasoconstriction and arterial vasoconstriction. $\mathrm{PCOOH}$ is positively correlated with the increased oxLDL concentration, but not related with native LDL (A). Different doses of native LDL $(0,0 ; 0.24, \boldsymbol{\Delta} ; 0.48, \mathbf{m} ; 0.72 \mathrm{mg}$ protein/ $\mathrm{mL}, \diamond$; and $0.72 \mathrm{mg}$ protein $/ \mathrm{mL}+$ catechins in 10 $\mathrm{mg} / \mathrm{kg}, \diamond)$, oxLDL $(0,0 ; 0.24, \boldsymbol{\Delta} ; 0.48, \mathbf{\square} ; 0.72 \mathrm{mg}$ protein $/ \mathrm{mL}, \diamond$; and $0.72 \mathrm{mg}$ protein $/ \mathrm{mL}+$ catechins in $10 \mathrm{mg} / \mathrm{kg}, \diamond)$, and PCOOH $(0,0 ; 61.6, \mathbf{\Delta} ; 123$, $\mathbf{~}$; $185 \mathrm{pmole} / \mathrm{mL}, \diamond$; and $185 \mathrm{pmole} / \mathrm{mL}+$ catechins in $10 \mathrm{mg} / \mathrm{kg}, \diamond)$, and PCOOH (0, ०; 61.6, $\mathbf{A} ; 123$, .; 185 pmole $/ \mathrm{mL}+$ catechins in $10 \mathrm{mg} / \mathrm{kg}, \diamond$ ) on aortic and renal blood flow in urethane anesthetized rats in vivo were determined. oxLDL and $\mathrm{PCOOH}$, but not LDL caused renal (B) and aortic vasoconstriction (C) in a dose-dependent manner. The data are expressed as percentages of reduction in blood flow. The basal aortic blood flow and renal blood flow were 10.5 \pm 1.2 $\mathrm{mL} / \mathrm{min}$ and $3.6 \pm 0.4 \mathrm{~mL} / \mathrm{min}$, respectively. ${ }^{*} \mathrm{P}<0.05$, vs. each saline control; \# $\mathrm{P}<0.05$ between saline and catechins treatment of oxLDL or PCOOH group. 


\section{Kidney \\ Blood Pressure \\ Research}

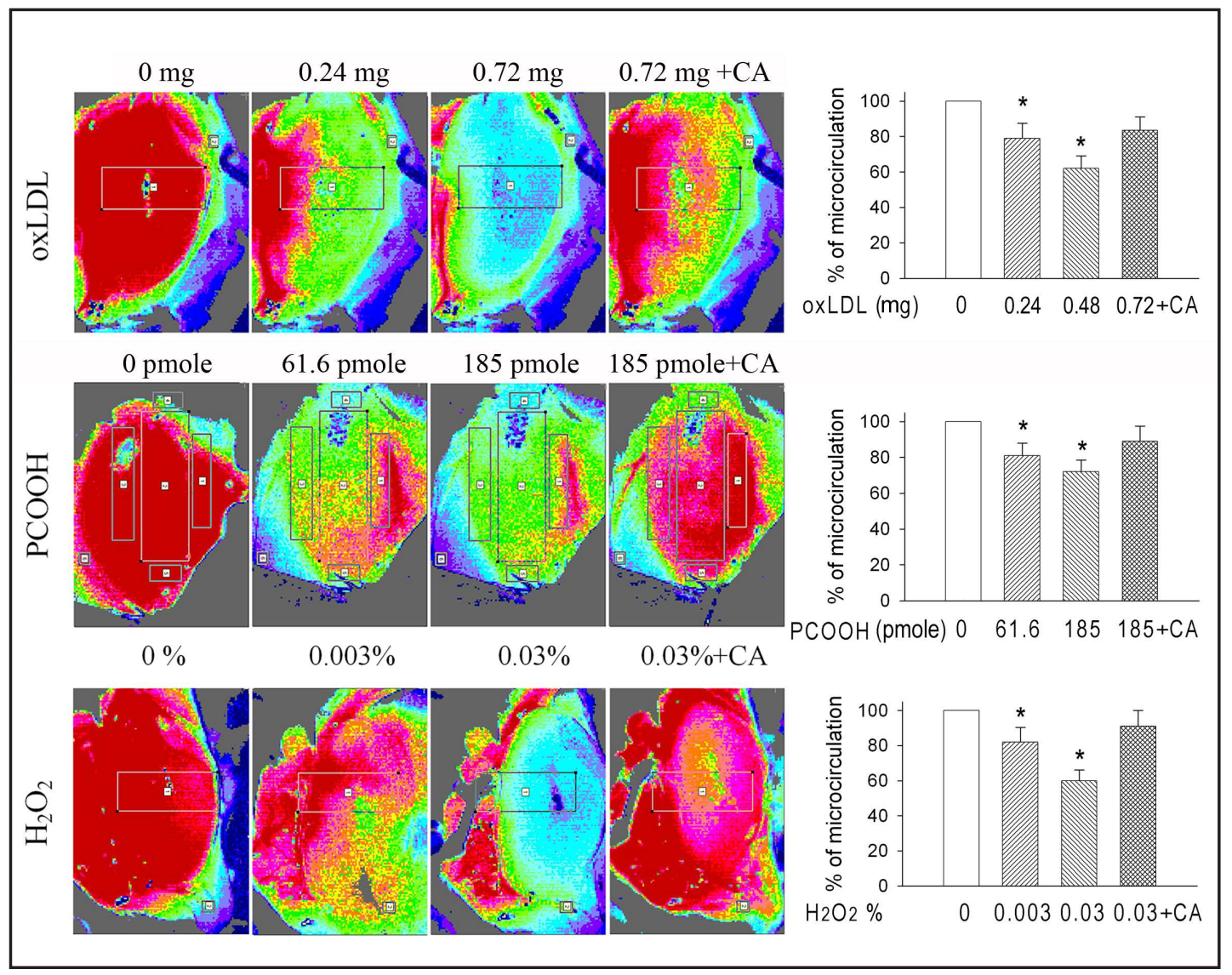

Fig. 4. Effect of intravenous $\mathrm{PCOOH}$, oxLDL and $\mathrm{H}_{2} \mathrm{O}_{2}$ on renal microcirculation determined from the rat kidney in vivo. The effects of different dosage of $\mathrm{PCOOH}$, oxLDL or $\mathrm{H}_{2} \mathrm{O}_{2}$ on renal microcirculation by Moor Image were indicated. Blue color indicated a lower level of microcirculation, whereas red color demonstrated a higher microcirculation. PCOOH, oxLDL and $\mathrm{H}_{2} \mathrm{O}_{2}$ dose-dependently decreased renal microcirculation, whereas catechins (CA) pretreatment efficiently recovered the depressed renal microcirculation by $\mathrm{POOH}$, oxLDL or $\mathrm{H}_{2} \mathrm{O}_{2}$ in rats. ${ }^{*} \mathrm{P}<0.05$, vs. each group with saline control $(0 \mathrm{mg}, 0$ pmole or $0 \%)$.

Oral catechins depressed oxLDL- or PCOOH-enhanced renal ICAM-1 expression and 4-HNE immunoreactivity and preserved oxLDL- or PCOOH-reduced renal eNOS expression

The effect of catechins on renal ICAM-1, eNOS expression and 4-HNE immunoreactivity after intravenous oxLDL or $\mathrm{PCOOH}$ were evaluated. We found that 4 hours after intravenous oxLDL or PCOOH, stimulation significantly $(P<0.05)$ reduced renal eNOS expression (Figures $5 \mathrm{~A}$ and $5 \mathrm{~B})$ and significantly $(P<0.05)$ enhanced two oxidative stress biomarkers, the renal ICAM-1 expression (Figures 5C and 5D) and 4-HNE accumulation and immunoreactivity (Figures 5E and 5F). Different dosages of oxLDL ( $0.24 \mathrm{mg}$ or $0.72 \mathrm{mg}$ ) and PCOOH (61.6 pmole or 185 pmole) significantly, but not dose-dependently, decreased renal eNOS expression. The dosage of oxLDL at $0.24 \mathrm{mg}$ or $0.72 \mathrm{mg}$ significantly and dose-dependently enhanced renal ICAM-1 expression. The dosage of PCOOH at $61.6 \mathrm{pmole} / \mathrm{mL}$ or $185 \mathrm{pmole} / \mathrm{mL}$ significantly (not dose-dependently) enhanced renal ICAM-1 expression. OxLDL or PCOOH significantly, but not dose-dependently, increased 4-HNE immunoreactivity.

Oral catechins depressed oxLDL- or PCOOH-enhanced urinary 8-isoprostane levels and preserved oxLDL- or PCOOH-decreased urinary nitrite/nitrate concentration

We measured urinary 8-Isoprostane levels as a marker and regulator for oxidative stress [17], the nitrite and nitrate originated from nitric oxide regulated by eNOS [18] in response to oxLDL or $\mathrm{PCOOH}$ stimulation. The results showed that intravenous oxLDL 


\section{Kidney \\ Blood Pressure Research}

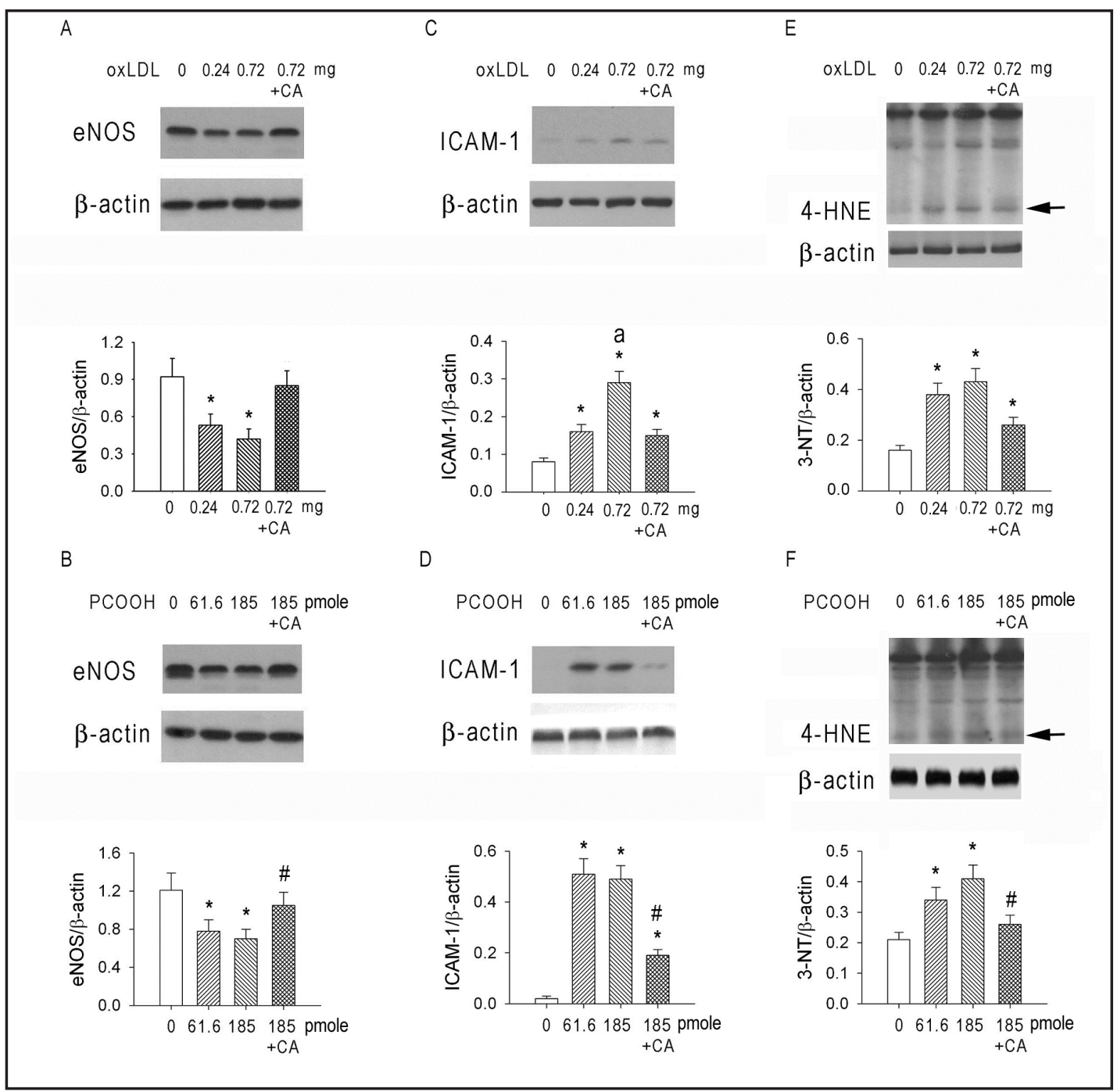

Fig. 5. Effect of catechins on intravenous oxLDL or PCOOH-enhanced eNOS expression (A, B), ICAM-1 expression (C, D) and entire 4-HNE immunoreactivity (E, F) in the rat kidney. Each experiment from whole kidney homogenates was performed three times. * $\mathrm{P}<0.05$ vs. saline control (0). a $\mathrm{P}<0.05$ oxLDL at $0.72 \mathrm{mg}$ vs. oxLDL $0.24 \mathrm{mg}$ treatment. b $\mathrm{P}<0.05$ oxLDL at $0.72 \mathrm{mg}+\mathrm{CA}$ vs. oxLDL at $0.72 \mathrm{mg}$ treatment.\# $\mathrm{P}<0.05$ $\mathrm{PCOOH}$ at 185 pmole + CA vs. PCOOH at 185 pmole treatment. CA, catechins.

significantly elevated the 8-isoprostane levels in the urine at a dose-dependent manner (Figure 6A). Intravenous oxLDL significantly decreased the urinary nitrite (Figure 6B) and nitrate concentration at a dose dependent manner (Figure 6C), implicating the impairment of eNOS-mediated vasorelaxation activity by NO. The use of catechins supplement significantly decreased oxLDL elevated urinary 8-isoprostane levels and preserved oxLDL decreased urinary nitrite and nitrate concentration.

Intravenous $\mathrm{PCOOH}$ dose dependently and significantly increased the 8-isoprostane levels in the urine (Figure 6D) associated with the significant reduction of urinary nitrite (Figure 6E) and nitrate concentration (Figure 6F) in a dose-dependent manner, suggesting the impairment of eNOS-mediated NO production and activity. The application of catechins significantly decreased $\mathrm{PCOOH}$ enhanced urinary 8-isoprostane levels and preserved $\mathrm{PCOOH}$ decreased urinary nitrite and nitrate concentration. 


\section{Kidney Blood Pressure Research}

\section{Discussion}

In this study, $\mathrm{PCOOH}$ increased the $\mathrm{H}_{2} \mathrm{O}_{2}$ levels and the percentage of apoptosis in the HUVECs. In addition, the concentration of $\mathrm{PCOOH}$ was highly and positively correlated with oxLDL in rats. These findings support that oxLDL or $\mathrm{PCOOH}$ increases $\mathrm{H}_{2} \mathrm{O}_{2}$ which plays a role in endothelial cell injury. We further displayed that oxLDL or PCOOH would cause vasoconstriction in vivo in a dose-dependent manner. Catechins treatment reduced $\mathrm{PCOOH}$-induced endothelial $\mathrm{H}_{2} \mathrm{O}_{2}$ and apoptosis in HUVECs implicating catechins' protective effect on endothelial cells. Moreover, oral catechins administration to rats showed to reduce $\mathrm{PCOOH}$-enhanced plasma $\mathrm{H}_{2} \mathrm{O}_{2}$ activities, 4-HNE accumulation, ICAM1 expression, palliated oxLDL-, PCOOH- or H2O2-enhanced vasoconstriction, decreased urinary isoprostane concentration and restored eNOS expression and NO activity. These results provide evidence suggesting catechin as a supplement for reducing oxLDL related cardiovascular risk through attenuation of ROS injury.

PCOOH, the primary metabolite of oxLDL, increased the $\mathrm{H}_{2} \mathrm{O}_{2}$ levels and the percentage of apoptosis in the HUVECs which could be attenuated by catalase or catechins. The results suggest that $\mathrm{H}_{2} \mathrm{O}_{2}$ mediated endothelial cell injury plays a role in oxLDL induced vascular injury and could be ameliorated by proper ROS scavengers. In addition, intravenous administration of oxLDL, PCOOH or $\mathrm{H}_{2} \mathrm{O}_{2}$ directly induced renal and aortic constriction by both the reduction of blood flow and microcirculation which contribute to the precipitation of atherosclerotic/ischemic vascular disease. Oxidized LDL was known to enhance norepinephrine, serotonin, phenylephrine or potassium induced vasoconstrictions by a direct effect on the vascular smooth muscle [5]. However, the detailed mechanism of the oxLDL-induced enhancement of contractile responses remains to be determined. $\mathrm{H}_{2} \mathrm{O}_{2}$ directly modulates phenylephrine-induced contractile response in renal hypertensive rat aorta [19]. Increased ROS bioavailability along with decreased NO production and increased
B

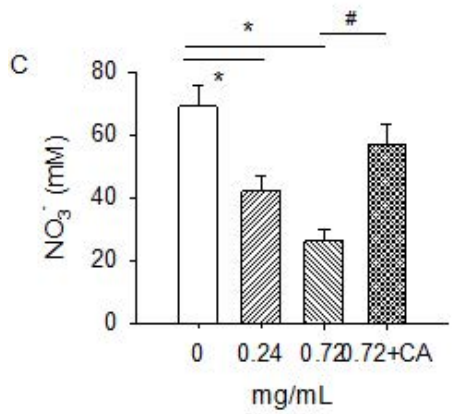

Fig. 6. The effect of catechins on intravenous oxLDL or PCOOH mediated urinary 8-isoprostane and $\mathrm{NO}$ metabolites $\left(\mathrm{NO}_{2}^{-}\right.$and $\left.\mathrm{NO}_{3}^{-}\right)$ levels. A-C: oxLDL effect; D-F: PCOOH effect. ${ }^{*} \mathrm{P}<0.05$ vs. saline control $\mathrm{mg} / \mathrm{mL}$ in oxLDL or $0 \mathrm{pmole} / \mathrm{mL}$ in $\mathrm{PCOOH}$ ). \# $\mathrm{P}<0.05$ oxLDL 0.72 $\mathrm{mg} / \mathrm{mL}+\mathrm{CA}$ vs. oxLDL $0.72 \mathrm{mg}$ treatment or PCOOH $185 \mathrm{pmole} / \mathrm{mL}+$ CA vs. 185 pmole/mL treatment. CA, catechins. 


\section{Kidney Blood Pressure Research}

Kidney Blood Press Res 2017;42:919-932

\begin{tabular}{|l|l|l|l|l}
\hline DOI: 10.1159/000485082 & (C) 2017 The Author(s). Published by S. Karger AG, Base \\
\hline
\end{tabular} Published online: November 22, 2017 www.karger.com/kb

NO consumption have been proposed to contribute to the events underlying endothelial injury. Reduced bioavailability of NO in the endothelium is an important precursor for impaired vasodilation and hypertension $[20,21]$. The renal arterial infusion of oxLDL greatly enhanced ischemia/reperfusion-induced ROS and inhibited nitric oxide bioactivity [18]. Other potential mechanisms such as isoprostanes, present in oxLDL can interact with the thromboxane A2 receptor (TP) [22], and 8-isoprostane inducing vasoconstriction had been reported [23]. Some studies demonstrated that the oxidation of lipoprotein enhanced the release of NO, IL-6, and ET-1, though with different kinetic characteristics and susceptibility to the TP-receptor blockade in microcirculation [24]. High oxLDL levels contribute to cardiovascular disease not only by traditional atheroma formation but also by direct ROS mediated endothelial injury and vasoconstriction.

Increased oxidative stress leads to the accumulation of 4-HNE aldehydes, proinflammatory ICAM-1 protein expression and activity and decrease eNOS expression and activity [8]. The accumulation of 4-HNE peroxidized lipids possibly leads to mitochondrial damage and subsequent programmed cell death. The initial stage of atherosclerotic plaque formation involves oxidation of the phosphatidylcholine moiety of LDL and subsequent uptake by macrophages [25]. Elevated $\mathrm{H}_{2} \mathrm{O}_{2}$ levels enhanced lipid peroxidation of LDL or VLDL and the increased oxLDL and PCOOH concentration induced vasoconstriction in renal microvascular beds [18], contributing to the accelerated progress of atherosclerosis in patients with exacerbated oxidative stress $[2,3,13]$. Therefore, ROS evoked by oxLDL or $\mathrm{PCOOH}$ may oxidize LDL resulting in increased oxLDL and whole condition becomes a vicious cycle. It is thus important to use a safe ROS scavenger to reduce oxLDL- or PCOOH-induced vasoconstriction, thereby breaking down the cycle and slowing down the progression of atherosclerotic and thrombotic vascular disease. The present study indicates that catechins can efficiently scavenge $\mathrm{O}_{2}, \mathrm{H}_{2} \mathrm{O}_{2}$, and $\mathrm{HOCl}$ in vitro and in vivo $[2,3,13]$ leading to the inhibition of atherosclerosis.

Adhesion molecules, such as ICAM-1, VCAM-1 and E-selectin, play important roles at the initial stage of atherosclerosis. Zhao et al [26]. indicated that oxLDL significantly induced ICAM-1, VCAM-1, and E-selectin expression at the mRNA and protein levels but reduced eNOS phosphorylation and NO generation. In their study, sodium nitroprusside, an NO donor, $\mathrm{N}$-acetyl-L-cysteine, a ROS scavenger, and BAY117082, a NF- $\kappa$ B inhibitor, were demonstrated to inhibit oxLDL-induced ICAM-1, VCAM-1, and E-selectin expression. Rahman et al [27]. reported that oxLDL but not native LDL caused vasoconstriction in isolated perfused rat kidney as evidenced by a significant dose dependent reduction in renal perfusate flow. NO synthase inhibitor N-monomethyl-L-arginine significantly increased and the NO donor nitrosoglutathione and L-arginine significantly diminished the vasoconstrictory effect of oxLDL. Superoxide dismutase (SOD) and catalase both had a significant inhibitory effect and the combination of SOD and catalase almost completely abolished oxLDL-induced vasoconstriction. Increased oxidative stress may activate LOX-1, a main receptor of oxLDL, to induce ICAM-1 expression, whereas the inhibition of oxidative stress can reduce renal and aortic LOX-1 and ICAM-1 expression [28]. Our data showed that catechins could reduce oxLDL induced ICAM-1 production and restore eNOS.

Catechins act as safe, and effective antioxidants in vitro by scavenging ROS, chelating redox-active transition metal ions [29], inhibiting the redox-sensitive transcription factors, NF-B and AP-1 [14, 29], depressing "pro-oxidant" enzymes, such as inducible nitric oxide synthase, lipoxygenases, cyclooxygenases and xanthine oxidase and increasing phase II and antioxidant enzymes, such as glutathione S-transferases and superoxide dismutases [29]. Tea flavonoid EGCG depressed oxLDL-enhanced ICAM-1 and VCAM-1 expression and reduced leukocytes infiltration to the vasculature by downregulating E-selectin and interleukin-1 from monocytes and NF- $\kappa B$ activation [30]. Our previous study evidenced that catechins supplement in end-stage renal disease patients can reduce hemodialysis-enhanced ROS [2, 13] and possibly attenuating oxLDL- and $\mathrm{PCOOH}$-mediated vasoconstriction. In that study, we had further indicated that along with $\mathrm{H}_{2} \mathrm{O}_{2}$ scavenging ability, the scavenging $\mathrm{HOCl}$ activity 


\section{Kidney \\ Blood Pressure Research}

of catechins can preserve paraoxonase 1 activity in counteracting oxLDL-induced vascular injury [13]. Preserved paraoxonase 1 activity in HDL has been reported to counteract oxLDLinduced oxidative stress, whereas a loss or attenuation of paraoxonase 1 activity may increase the susceptibility to atherosclerosis [31]. In the present study in rats, we provided direct evidence that catechins supplement reduced oxLDL- or PCOOH-mediated aortic and renal vasoconstriction, lipid peroxide 4-HNE accumulation, and ICAM-1 expression and preserved eNOS activity and expression. Given our previous report [13] has evidenced that chronic green tea extract supplementation in $455 \mathrm{mg}$ or $910 \mathrm{mg}$ per day reduces hemodialysisenhanced production of hydrogen peroxide and hypochlorous acid, atherosclerotic factors, and proinflammatory cytokines. The appropriate dose of catechins for effectively decreasing oxLDL induced cardiovascular events in the patients requires further studies.

In comparison to other available antioxidants, catechins and vitamin $\mathrm{C}$, but not vitamin E, can provide protection from oxidized LDL-induced leukocyte adhesion to microvascular and macrovascular endothelium in vivo [32]. Vitamin C protects human vascular smooth muscle cells against apoptosis induced by moderately oxLDL containing high levels of lipid hydroperoxides or PCOOH [33]. However, long-term, low-dose, intravenous vitamin C may lead to plasma calcium oxalate supersaturation in hemodialysis patients [34]. Catechins did not increase plasma calcium oxalate concentration and might further reduce $\mathrm{HOCl}$ amounts compared to vitamin C [13]. Catechins could be an appropriate option of an anti-oxidant supplement for reducing oxLDL related cardiovascular disease.

\section{Conclusion}

The present study demonstrated that oxLDL through its primary metabolite, PCOOH, reduces arterial blood flow by an ROS-mediated vasoconstriction. In endothelial cell culture, $\mathrm{PCOOH}$ induced endothelial cell death through $\mathrm{H}_{2} \mathrm{O}_{2}$-mediated apoptosis, whereas catechins or catalase decreased $\mathrm{H}_{2} \mathrm{O}_{2}$ levels and recovered PCOOH-induced cell apoptosis. In the rat study, the increased plasma catechins by oral supplement significantly inhibited oxLDL-, PCOOH- or $\mathrm{H}_{2} \mathrm{O}_{2}$-induced renal and aortic vasoconstriction, decreased urinary 8-isoprostane levels, renal ICAM-1 expression and 4-HNE accumulation, restored nitrite/ nitrate amounts, and eNOS activity. Our data suggest that catechins decrease oxLDL- or PCOOH-induced endothelial cell apoptosis and vasoconstriction through $\mathrm{H}_{2} \mathrm{O}_{2}$ inhibition and eNOS restoration. These in vitro and in vivo data suggest that catechins supplements may be intrumental in reducing oxLDL-induced cardiovascular diseases.

\section{Disclosure Statement}

There are no known conflicts of interest associated with this publication and there has been no significant financial support for this work that could have influenced its outcome.

\section{Acknowledgements}

This work was partly supported by the National Science Council of the Republic of China (NSC 92-2320-B002-078) and Kuang-Tien General Hospital Research Funds (CR-A0410002). 


\section{Kidney \\ Blood Pressure Research}

Chang et al.: Catechins Reduce PCOOH-Induced Endothelial Injury

\section{References}

1 Halliwell B: Biochemistry of oxidative stress. Biochem Soc Trans 2007;35:1147-1150.

2 Huang KC, Yang CC, Lee KT, Chien CT: Reduced hemodialysis-induced oxidative stress in end-stage renal disease patients by electrolyzed reduced water. Kidney Int 2003;64:704-714.

-3 Chien CT, Chang WT, Chen HW, Wang TD, Liou SY, Chen TJ, Chang YL, Lee YT, Hsu SM: Ascorbate supplement reduces oxidative stress in dyslipidemic patients undergoing apheresis. Arterioscler Thromb Vasc Biol 2004;24:1111-1117.

4 Quinn MT, Parthasarathy S, Fong LG, Steinberg D: Oxidatively modified lipoproteins: a potential role in recruitment and retention of monocyte/macrophages during atherogenesis. Proc Natl Acad Sci USA 1987; 84:2995-2998.

-5 Galle J, Bassenge R, Busse R: Oxidized low-density lipoproteins potentiate vasoconstrictions to various agonists by direct interaction with vascular smooth muscle. Circ Res 1990;66:1287-1293.

6 Sethy-Coraci I, Crock LW, Silverstein SC: PAF-receptor antagonists, lovastatin, and the PTK inhibitor genistein inhibit $\mathrm{H}_{2} \mathrm{O}_{2}$ secretion by macrophages cultured on oxidized-LDL matrices. J Leukoc Biol 2005;78:1166-1174.

7 Chao CL, Kuo TL, Lee YT: Effects of methionine-induced hyperhomocysteinemia on endotheliumdependent vasodilation and oxidative status in healthy adults. Circulation 2000;101:485-490.

8 Chien CT, Fan SC, Lin SC, Kuo CC, Yang CH, Yu TY, Lee SP, Cheng DY, Li PC: Glucagon-like peptide-1 receptor agonist activation ameliorates venous thrombosis-induced arteriovenous fistula failure in chronic kidney disease. Thromb Haemost 2014;112:1051-1064.

-9 Hoffmann J, Haendeler J, Aicher A, Rössig L, Vasa M, Zeither AM, Dimmeler S: Aging enhances the sensitivity of endothelial cells toward apoptotic stimuli: important role of nitric oxide. Circ Res 2001;89:709-715.

-10 Uraoka M, Ikeda K, Kurimoto-Nakano R, Nakagawa Y, Koide M, Akakabe Y, Kitamura Y, Ueyama T, Matoba S, Yamada H, Okigaki M, Matsubara H: Loss of bcl-2 during the senescence exacerbates the impaired angiogenic functions in endothelial cells by deteriorating the mitochondrial redox state. Hypertension 2011;58:254-263.

11 Bjelakovic G, Nikolova D, Gluud C: Antioxidant supplements and mortality. Curr Opin Clin Nutr Metab Care 2014;17:40-44.

-12 Hertog MG, Feskens EJ, Hollman PC, Katan MB, Kromhout D: Dietary antioxidant flavonoids and risk of coronary heart disease: the Zutphen Elderly Study. Lancet 1993;342:1007-1011.

13 Hsu SP, Wu MS, Yang CC, Huang KC, Liou SY, Hsu SM, Chien CT: Chronic green tea extract supplementation reduces hemodialysis-enhanced production of hydrogen peroxide and hypochlorous acid, atherosclerotic factors, and proinflammatory cytokines. Am J Clin Nutr 2007;86:1539-1547.

14 Yu HJ, Lin BR, Lee HS, Shun CT, Yang CC, Lai TY, Chien CT, Hsu SM: Sympathetic vesicovascular reflex induced by acute urinary retention evokes proinflammatory and proapoptotic injury in rat livers. Am J Physiol Renal Physiol 2005;288:F1005-F1014.

15 Chung SD, Lai TY, Chien CT, Yu HJ: Activating Nrf-2 signaling depresses unilateral ureteral obstructionevoked mitochondrial stress-related autophagy, apoptosis and pyroptosis in kidney. PLoS One 2012;7:e47299.

16 Muzykantov VR: Targeting of superoxide dismutase and catalase to vascular endothelium. J Control Release 2001;71:1-21.

17 Montuschi P, Barnes PJ, Roberts LJ $2^{\text {nd: }}$ Isoprostanes: markers and mediators of oxidative stress. FASEB J 2004;18:1791-1800.

18 Lee CM, Chien CT, Chang PY, Hsieh MY, Jui HY, Liau CS, Hsu SM, Lee YT: High-density lipoprotein antagonizes oxidized low-density lipoprotein by suppressing oxygen free-radical formation and preserving nitric oxide bioactivity. Atherosclerosis 2005;183:251-258.

19 Silva BR, Pernomian L, Grando MD, Amaral JH, Tanus-Santos JE, Bendhack LM: Hydrogen peroxide modulates phenylephrine-induced contractile response in renal hypertensive rat aorta. Eur J Pharmacol 2013;721:193-200.

-20 Zhang YH: Neuronal nitric oxide synthase in hypertension - an update. Clin Hypertens 2016;22:20. 


\section{Kidney \\ Blood Pressure Research}

21 Yang CC, Yao CA, Yang JC, Chien CT: Sialic acid rescues repurified lipopolysaccharide-induced acute renal failure via inhibiting TLR4/PKC/gp91-mediated endoplasmic reticulum stress, apoptosis, autophagy, and pyroptosis signaling. Toxicol Sci 2014;141:155-165.

-22 Delannoy E, Courtois A, Freund-Michel V, Leblais V, Marthan R, Muller B: Hypoxia-induced hyperreactivity of pulmonary arteries: role of cyclooxygenase-2, isoprostanes, and thromboxane receptors. Cardiovasc Res 2010;85:582-592.

-23 Cracowski JL, Devillier P, Durand T, Stanke-Labesque F, Bessard G: Vascular biology of the isoprostanes. J Vasc Res 2001;38:93-103.

24 Lubrano V, Baldi S, Ferrannini E, L'Abbate A, Natali A: Role of thromboxane A2 receptor on the effects of oxidized LDL on microvascular endothelium nitric oxide, endothelin-1, and IL-6 production. Microcirculation 2008;15:543-53.

25 Piotrowski JJ, Shah S, Alexander JJ: Mature human atherosclerotic plaque contains peroxidized phosphatidylcholine as a major lipid peroxide. Life Sci 1996;58:735-740.

26 Zhao W, Wu C, Chen X: Cryptotanshinone Inhibits oxidized LDL-Induced Adhesion Molecule Expression via ROS Dependent NF- $\kappa$ B Pathways. Cell Adh Migr 2016;10:248-258.

27 Rahman, MM, Varghese, Z, Fuller, BJ, Moorhead, JF: Renal vasoconstriction induced by oxidized LDL is inhibited by scavengers of reactive oxygen species and L-arginine. Clin Nephrol 1999;51:98-107.

28 Wang LJ, Yu YH, Zhang LG, Wang Y, Niu N, Li Q Guo LM: Taurine rescues vascular endothelial dysfunction in streptozocin-induced diabetic rats: correlated with downregulation of LOX-1 and ICAM-1 expression on aortas. Eur J Pharmacol 2008;597:75-80.

29 Frei B, Higdon JV: Antioxidant activity of tea polyphenols in vivo: evidence from animal studies. J Nutr 2003;133;3275S-3284S.

-30 Ludwig A, Lorenz M, Grimbo N, Steinle F, Meiners S, Bartsch C, Stangl K, Baumann G: The tea flavonoid epigallocatechin-3-gallate reduces cytokine-induced VCAM-1 expression and monocyte adhesion to endothelial cells. Biochem Biophys Res Commun 2004;316:659-665.

-31 Sutherland WH, Walker RJ, de Jong SA, van Rij AM, Phillips V, Walker HL: Reduced postprandial serum paraoxonase activity after a meal rich in used cooking fat. Arterioscler Thromb Vasc Biol 1999;19:13401347.

-32 Lehr HA, Frei B, Olofsson AM, Carew TE, Arfors KE: Protection from oxidized LDL-induced leukocyte adhesion to microvascular and macrovascular endothelium in vivo by vitamin $\mathrm{C}$ but not by vitamin $\mathrm{E}$. Circulation 1995;91:1525-1532.

-33 Siow RC, Richards JP, Pedley KC, Leake DS, Mann GE: Vitamin C protects human vascular smooth muscle cells against apoptosis induced by moderately oxidized LDL containing high levels of lipid hydroperoxides. Arterioscler Thromb Vasc Biol 1999;19:2387-2394.

-34 Canavese C, Petrarulo M, Massarenti P, Berutti S, Fenoglio R, Pauletto D, Lanfranco G, Bergamo D, Sandri L, Marangella M: Long-term, low-dose, intravenous vitamin C leads to plasma calcium oxalate supersaturation in hemodialysis patients. Am J Kidney Dis 2005;45:540-549. 